\title{
Fteknokultura
}

\#SuÁreZ, M. (2016). Colectivos sociales y ciborgs: hacia una lectura feminista de los drones, Revista TeknokulturaVol. 13(1), 271-288.

Recibido: 31-01-2016

Aceptado: 18-04-2016
Open peer review

http://revistas.ucm.es/index.php/TEKN/pages/view/opr-49798

\section{Colectivos sociales $y$ ciborgs: hacia una lectura feminista de los drones}

Social collectives and cyborgs: towards a feminist perspective on drones

\author{
Marcela Suárez \\ marce.srz@gmail.com \\ Freie Universität Berlin
}

\section{Resumen}

Este artículo analiza el papel de los drones en la emergencia de nuevas formas de participación política e impugnación del poder por parte de colectivos sociales. El artículo plantea una lectura feminista de los drones como ciborgs (humanos-máquinas) para explorar las agencias distribuidas entre actores humanos y no humanos con el propósito de visibilizar las relaciones de poder y analizar la configuración de contra-realidades. Se presentan ocho 
casos de colectivos sociales que, con la ayuda de un dron, disputan el poder de gobiernos, empresas transnacionales además de desempeñar innovadoras intervenciones públicas.

\section{Palabras Clave}

movimientos sociales; contra-cultura; vehículos aéreos no tripulados.

\section{Abstract}

This article analyses the role of drones in the emergence of new forms of political participation and power contestation by social collectives. It deploys a feminist perspective that presents drones as cyborgs (human-machines) to explore human and non-human agencies, make visible the power relations that are mobilized, and to comprehend the configuration of counter-realities. Eight cases are presented of social collectives that with the help of drones perform public interventions and contest the power of governments and transnational companies.

\section{KeYWORDS}

social movements; counter-culture; unmanned aerial vehicles (drones).

\section{Contenidos}

1. Introducción: los drones activistas

2. Materialidad, ciborgs y activismos tecnocientíficos

3. Drones y colectivos sociales: integrando agencias humanas y no humanas

4. Reflexiones finales: una mirada feminista a los drones

5. Referencias 


\section{Contents}

1. Introduction: activist drones

2. Materialities, cyborgs and technoscientific activisms

3. Drones and social collectives: integrating human and non-human agencies

4. Final reflections: a feminist perspective on drones

5. References 



\section{Introducción: los drones activistas}

¿Cuál es el común denominador entre los lienzos de un artista en Nueva York, la distribución de pastillas para abortar en Słubice y las protestas en las calles de la Ciudad de México? La respuesta es drones, conocidos formalmente como vehículos aéreos no tripulados (UAV por sus siglas en ingles) son operados por control remoto o de forma autónoma programados por computadora desde la tierra. Es una nueva tecnología situada en la intersección entre innovadoras aplicaciones globales comerciales, gubernamentales, militares, civiles $^{1}$ y hasta políticas. En varias ciudades como Nueva York, Słubice y la Ciudad de México, los drones, junto con los colectivos sociales, impulsan nuevas formas de participación política e impugnan el poder de gobiernos y empresas trasnacionales a través de intervenciones en el espacio público.

Ante este contexto, ¿qué significa llevar a cabo una lectura feminista de los drones? ¿Por qué resulta necesaria? Una respuesta posible: para descentrar la atención de las clásicas miradas de género que cuantifican la asimetría entre hombres y mujeres que vuelan drones o que destacan las dificultades que enfrentan las mujeres al operar los mismos (Komarovsky, 1950; Stone, 2015). Por ello, este artículo no plantea incrementar el número de mujeres que operan drones y de este modo establecer un equilibrio de género. Más bien, una lectura feminista supone un reto por visibilizar las estrategias de contra-cultura de este tipo de tecnología como ciborgs, como mapas de poder e identidad (Haraway, 2004), como metáforas de humanos-máquinas con agencias distribuidas en la generación de conocimiento civil, como mediadores en la extensa red de actores humanos y no humanos en intervenciones activistas.

Por contra-cultura me refiero aquí a las prácticas de cuestionamiento, oposición y elaboración de propuestas alternativas a sistemas de dominación hegemónicos. En este artículo haré referencia en particular a tres perspectivas feministas que brindarán los elementos teóricos relacionados con el poder para analizar los drones y su papel en la acción colectiva. La primera está relacionada con el feminismo como una práctica activista (Chávez, 2010; Conway, 2011; Feigenbaum, 2015; Sandoval \& Latorre, 2008), la segunda con la propuesta que hacen las literaturas feministas tecnocientíficas en mitigar las divisiones entre actores humanos y no humanos que visibilicen las relaciones de poder (Barad, 2003; Haraway,

\footnotetext{
${ }^{1}$ Por ejemplo en actividades científicas y de investigación; en la filmación de películas y documentales; en la gestión de los desastres naturales; en la construcción y la agricultura; en emergencias humanitarias; proyectos arqueológicos; así como en el arte, el diseño y la arquitectural.
} 
2004; Suchman, 2007) y la tercera se basa en la idea de los feminismos globales que no sólo contribuyen con brindar las herramientas teóricas y analíticas para abordar cuestiones de género, sino también con explicar diversos fenómenos sociales a escala global (Connell, 2013, 2015).

El propósito en este texto es aportar una lectura feminista de las agencias distribuidas entre colectivos sociales y drones para generar estrategias de contra-evidencia, contra-vigilancia y contra-cultura. En este intento hago visibles las prácticas de disputa del poder de gobiernos y empresas transnacionales, así como las huellas del artivismo en los espacios públicos. A través de diversos casos de colectivos sociales, espero contribuir con el análisis del papel que tiene la visión y el conocimiento civil en la configuración de realidades para contrarrestar los discursos de los privilegiados respecto al uso de drones.

\section{Materialidad, ciborgs y activismos tecnocientíficos}

Diferentes perspectivas feministas proponen trascender las divisiones y binarismos clásicos entre hombres/mujeres, significado/práctica, agencia/estructura, hombre/máquina, ciencia/tecnología, discurso/materialidad que configuran nuestras realidades, para en cambio explorar los diferentes significados en ensamblajes socio-materiales (Barad, 2007; Halberstam, 1991; Haraway, 1991; Suchman, 2007). Los autores/as han propuesto metáforas y conceptos para reflexionar la constante tensión entre las nociones de materia, discurso, agencia, y poder, y analizar así las formas en que humanos y no humanos, fenómenos naturales y no naturales convergen en redes híbridas.

Haraway (1991, p. 149), por ejemplo, propone el ciborg como una metáfora humanomáquina que transgrede binarismos y visibiliza la manera en que lo natural y lo cultural, lo material y los significados están interconectados. De acuerdo con la autora, un ciborg es "un organismo cibernético, un híbrido entre humano y máquina, una creatura de la realidad, así como una creatura de la ficción" (Ibídem). Para Haraway, las máquinas de este siglo han hecho ambigua la diferencia entre lo natural y lo artificial, la mente y el cuerpo y otras distinciones que son normalmente aplicadas en organismos y máquinas (ídem., p. 152). La autora sugiere que la máquina no debe ser animada, idolatrada y dominada. La máquina, señala, es nosotras, nuestros procesos, así como un aspecto de nuestra personificación (ídem, p. 180). Es importante destacar que el Manifiesto Cyborg de Haraway fue escrito en un contexto tecnocientífico militar y de posguerra, de feminismos activistas anti militares y nucleares, de redes de protestas ante un sistema patriarcal y predador de la naturaleza. 
Suchman (2007), por su parte, sugiere el concepto de "acción situada" como una forma de reconceptualizar la interfaz entre humanos y no humanos y la constitución mutua entre ellos. Su propuesta es localizar la configuración de historias sociales y biografías individuales en personas y artefactos, lo que a su vez requiere localizar una red más extensa de agencias y configuraciones específicas entre entidades humanas y no humanas.

Por su parte Barad (2007, p. 133) argumenta que la performatividad es una forma de impugnación del excesivo poder otorgado al lenguaje para determinar las ontologías que determinan lo que es real, sin embargo, ha fracasado en proveer una adecuada comprensión de la relación entre los discursos científicos y las prácticas materiales. La autora propone el concepto de agential realism con el objetivo de cambiar la mirada que asume entidades separadas en la observación de un fenómeno, por una integración de la mutua constitución de objetos y agencias que provea una entendimiento del papel de humanos y no humanos, practicas materiales y discursivas, y fenómenos naturales y no naturales. De acuerdo a Barad (2007, p. 137), la materia es agentiva; la agencia no es sólo un atributo de los actores, en cambio es una reconfiguración en proceso constante (ídem, p. 141). Así, de acuerdo con la autora, los artefactos no se encuentran sólo en el mundo, sino en reconfiguraciones dinámicas materiales del mundo. La dinámica es la agencia.

Con base a estas propuestas, una lectura feminista de los drones conecta la acción colectiva y la relación entre agencia y materia a través de una perspectiva renovada y más plural. Bajo esa mirada, la materialidad no es solamente discutida en términos de diseño, ventajas, usos y daños potenciales de una tecnología, sino que incorpora también el análisis los imaginarios, representaciones y relaciones de poder que visibilizan y reconfiguran.

\section{Drones y colectivos sociales: integrando agencias humanas y no humanas}

En esta sección destaco ocho casos en los que colectivos sociales y drones disputan el poder de gobiernos y empresas trasnacionales al tiempo que intervienen en el espacio público a través del artivismo. Una mirada feminista a los colectivos sociales y drones en diferentes ciudades no busca enfatizar binarismos espaciales relacionados con países desarrollados o en desarrollo, o Sur o Norte global. Por el contrario buscamos relaciones, conjunciones y yuxtaposiciones en lugar de promover comparaciones. 


\section{De luchas feministas y drones activistas}

Polonia, junto con Irlanda y Malta, son los tres países europeos donde el aborto no es legal. Cifras de la organización Women in Waves $^{2}$ señalan que existen alrededor de 40,000 abortos clandestinos cada año en Polonia que afectan sobre todo a mujeres de bajo recursos. El 27 de enero de 2015 un dron con dos paquetes de pastillas para abortar realizó un vuelo desde Frankfurt an der Oder, un pueblo en Brandemburgo (Alemania), cruzó el Río Oder que separa Alemania y Polonia, y aterrizó en Słubice (Polonia) (ver Figura 1). Dos mujeres polacas lograron tomar las pastillas tan pronto como eldron tocó la tierra. Del otro lado de la frontera, la policía alemana confiscó los controladores del dron y tabletas electrónicas personales. La acción fue resultado del trabajo de varios colectivos y organizaciones entre los que se encuentran Women on Waves, Cocia Basia, Feminteka Foundation from Warsaw, Porozumienie kobiet 8 marca, Berlin-Irish Pro Choice Solidarity, Codziennik Feministyczny y the Political group Twoj Ruch.

En abril de 2015, en Tokio (Japón), un dron aterrizó en el techo del edificio de la oficina del primer ministro de ese país como parte de las protestas por la reapertura de una planta de energía nuclear en Fukui. El dron tenía una cámara, una botella de plástico con arena de Fukushima y un símbolo que advierte la presencia de material radioactivo (el trébol radioactivo). Después del aterrizaje deldron, un hombre de Fukui se adjudico la acción a manera de protesta por la política energética nuclear del actual primer ministro.

El caso de Women in Waves muestra la reivindicación del feminismo como una práctica activista que, por un lado, denuncia los dispositivos de control social de los cuerpos femeninos en Polonia y, por otro, exige trascender divisiones y asimetrías entre países y fronteras. Por su parte, el dron japonés, a través de la denuncia de las transgresiones ambientales causadas en Fukushima en un acto que visibiliza la responsabilidad de las autoridades por la reapertura de las plantas nucleares, recuerda la vigencia del activismo feminista y anti nuclear del campamento por la paz de Greenham.

\footnotetext{
2 http://www.womenonwaves.org/en/page/650/who-are-we
} 


\section{FIGURA 1: $\quad$ LA DRON ACTIVISTA}

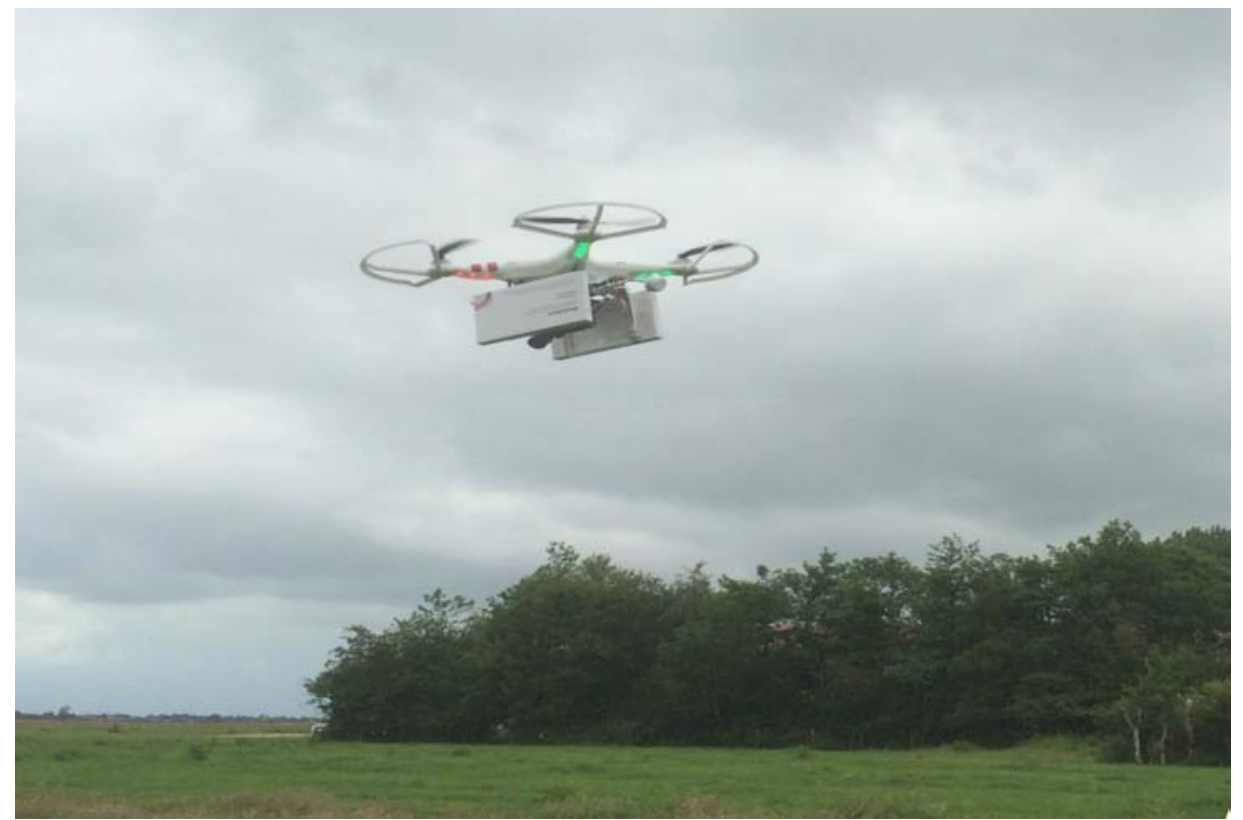

Fuente: Foto de Women in Waves.

\section{De contra-cartografías y mapas}

En Indonesia, como en varios otros países, gobiernos y empresas transnacionales apropian tierras y recursos naturales de las comunidades. En Kapuas River, Kalimatan, los drones están proveyendo contra-mapas usados en alegatos ante el gobierno local en la lucha contra la apropiación de tierras y bosques por parte de empresas mineras. En ese país se llevan a cabo movilizaciones sociales históricas y de participación ciudadana en la creación de contra-mapas mediante una serie de acciones-investigación (action-research) que buscan dar explicaciones a las grandes transformaciones en la región (Radjawali \& Pye, 2015).

Otro caso similar se encuentra en Rio de Janeiro (Brasil) donde está localizada la DroneHackademy. Es un prototipo de laboratorio ciudadano y una plataforma crítica para el uso de drones como una tecnología social ${ }^{3}$. En agosto de 2015, las actividades de Dronehackademy contribuyeron a crear una contra-cartografía aérea que visibiliza la amenaza de empresas

\footnotetext{
${ }^{3}$ Véase: http://dronehackademy.net/en/
} 
constructoras para las comunidades locales de Vila Autódromo en el marco de las obras de los juegos olímpicos en Rio de Janeiro 2016 (Figura 2). La cartografía consta de 20 fotografías de las 1,200 tomadas por un dron. La información generada aporta evidencia material a favor de la defensa legal de las comunidades movilizadas contra el proyecto de construcción del Parque Olímpico (de Soto, 2015).

\section{Figura 2: $\quad$ Contra-mapas en la comunidad de Vila Autódromo}

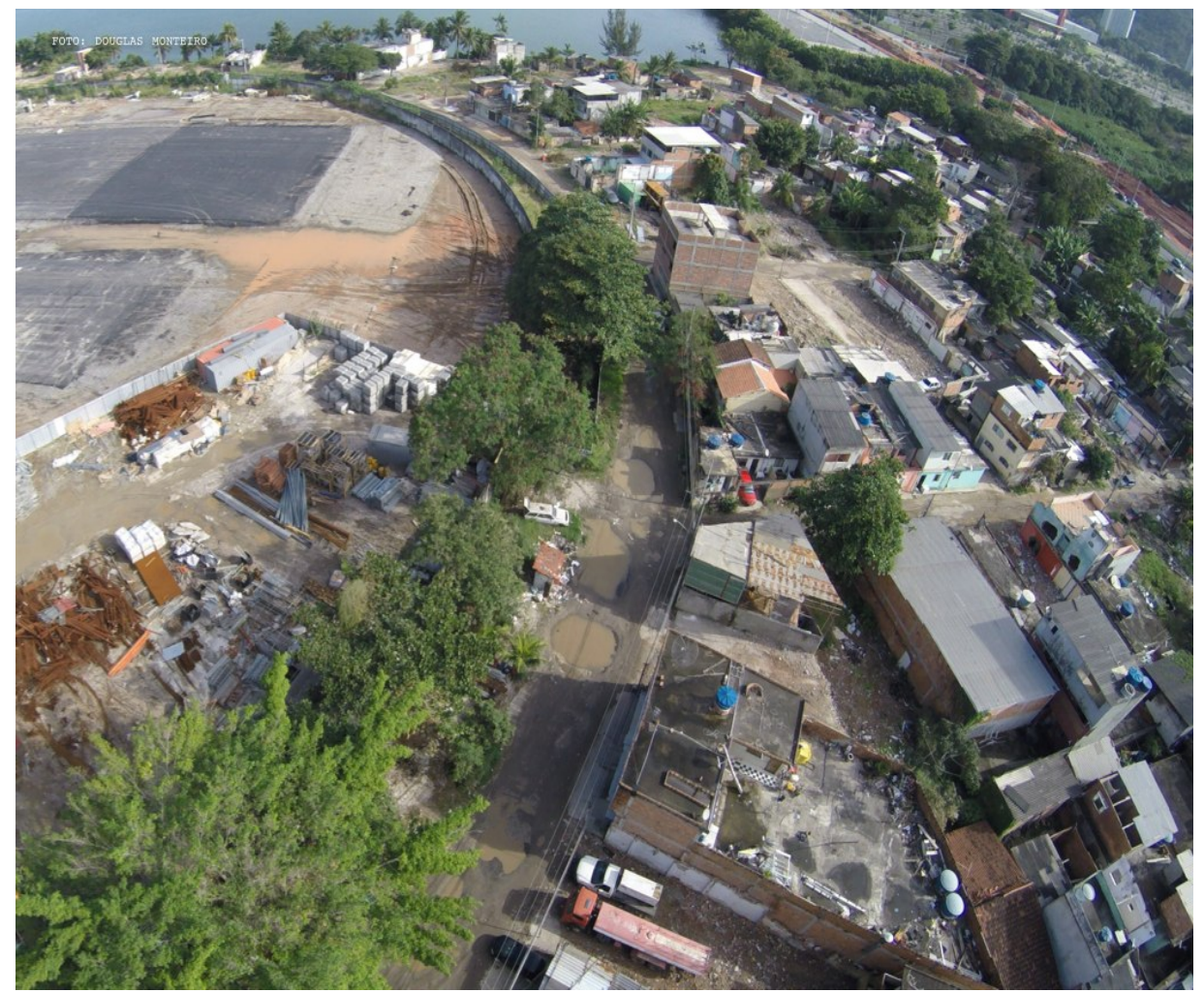

Fuente: Foto de Dronehackademy.

Los casos de Brasil e Indonesia recuerdan las advertencias feministas de no dividir entre agencias humanas y no humanas con el objeto de hacer visibles las relaciones de poder plasmadas en objetos materiales. En este sentido, los mapas están lejos de ser objetos técnicos y neutrales que solo representan la geografía de un paisaje terrenal, son en cambio materializaciones de procesos construidos con fines políticos que reflejan los intereses de quien los 
crea. Los drones así brindan opciones alternativas de visualización y representación que desafían las narrativas oficiales sobre la repartición de tierras o sobre los daños causados al medio ambiente. Las cartografías también son objetos que median las prácticas de organización colectiva y agencias empoderadas dentro de los colectivos sociales.

\section{De éticas, vigilancias y contra-vigilancias}

En la Ciudad de México el colectivo Rexiste ${ }^{4}$ realiza intervenciones en el espacio público con la ayuda de su así llamada pequeña hermana "Droncita". Juntos buscan incrementar la conciencia global acerca de las crecientes desapariciones, violaciones a los derechos humanos por parte militares y cuerpos policiacos, así como la criminalización de la protesta civil. Droncita lleva a cabo contra-vigilancia (fotos y videos) de las protestas en las calles de la Ciudad de México, como un mecanismo para disputar las versiones de los medios de comunicación, la policía y el gobierno local ante una creciente criminalización de la protesta civil en la ciudad. Este fue el caso de la marcha del 2 de octubre de 2015 que conmemora una matanza estudiantil de 1968. Al día siguiente de la marcha, los medios de comunicación proyectaron imágenes de grupos anarquistas con explosivos que no coinciden con las imágenes reales de las marchas donde civiles, mujeres, hombres, niñas, niños, colectivos sociales, trabajadoras y académicos marcharon de forma pacifica. Los videos y las fotos de Droncita ponen en evidencia la manipulación de la información por parte de los medios de comunicación y la alianza con el gobierno local y federal para la criminalización de la protesta social, así como los mecanismos de legitimación puestos en marcha que se traducen en una constante represión a los ciudadanos.

Otro caso lo encontramos en Alemania donde, en octubre de 2015, el colectivo Peng! voló un dron sobre el complejo Dagger en Darmstad, una base militar de Estados Unidos operada por la National Security Agency. El dron distribuyó panfletos a los más de 1,200 empleados de Dagger con información de la campaña "Intelexit". ${ }^{5}$ El objetivo de esta iniciativa era motivar y apoyar a los trabajadores de servicios secretos a que renuncien a sus trabajos por razones éticas.

Los casos de Droncita en la Ciudad de México e Intelexit en Darmstad permiten reflexionar tanto en los paralelismos entre los ciborgs y los drones, como en la relación entre las tecnologías y los sistemas de militares y de dominación a los que se refería Haraway en su

\footnotetext{
$4<$ http://rexiste.org/>

${ }^{5}$ Más información del colectivo y la campaña, se pueden encontrar en: $<$ https://pen.gg/intelexit>
} 
Manifiesto Cyborg. Si, como lo señala Haraway (2004), los ciborgs son descendientes ilegítimos del militarismo y del capitalismo, los drones activistas son descendientes rebeldes de esos mismos sistemas. No obstante, pertenecen a una nueva generación basada en algoritmos, prácticas de hipervigilancia y producción de datos (Feigenbaum, 2015). Los drones activistas son esa materialización de complejas relaciones sociotécnicas, pero también una herramienta crítica que trasciende, como lo señala Haraway (2004), las categorías fijas. Son una quimera en constante mutación que crea y destruye identidades, categorías, historias, espacios y relaciones (ídem, p. 39). Los drones son también esas máquinas que permiten mediar y extender la visión (Haraway, 1998) y el embodiment para configurar contra-realidades e impugnar discursos autoritarios y militares.

\section{De cambios, drone-graffitis y artivismos}

Figura 3: Droncita: "¡Es tiempo de CAMBiarlo todo!"

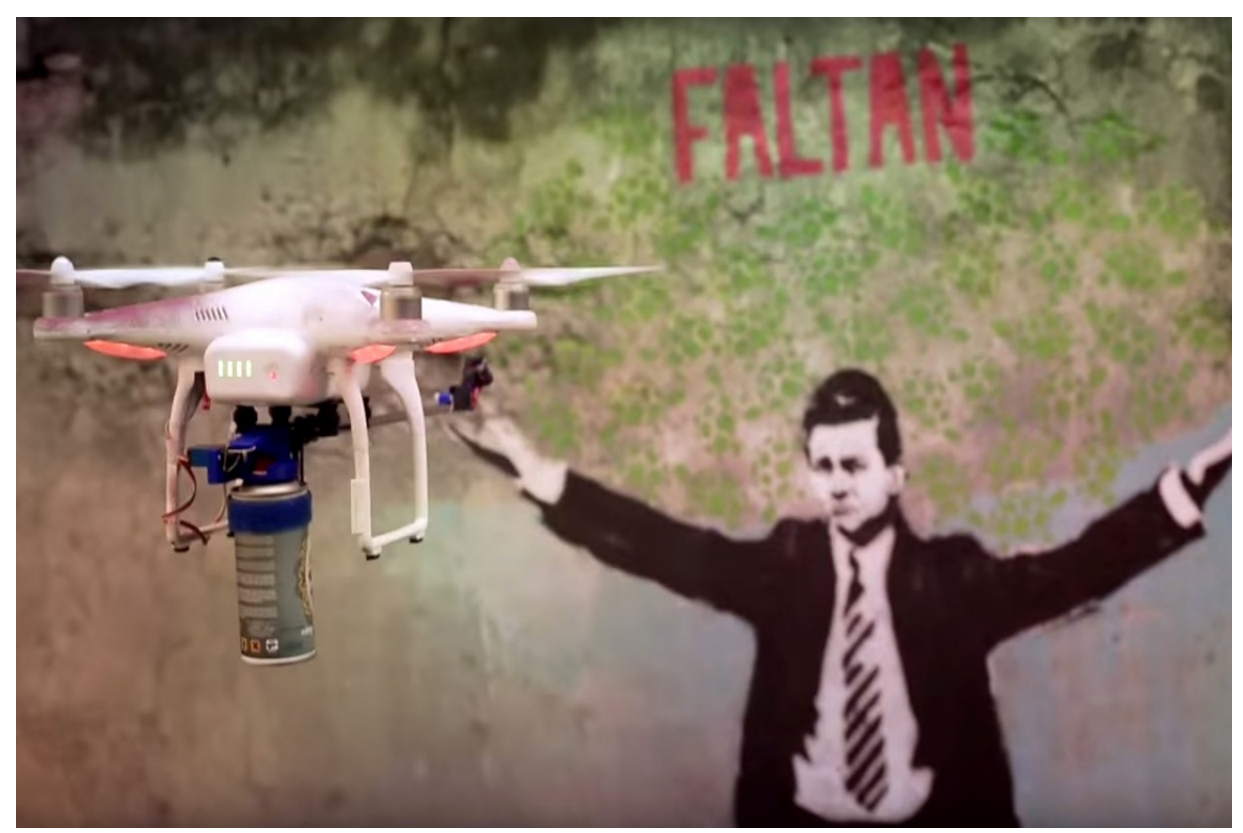

Fuente: Foto del Colectivo Rexiste.

La misma Droncita, del colectivo Rexiste, es una mujer-máquina preocupada por "cambiarlo todo" en México. Como parte de las protestas en el marco del aniversario de la 
desaparición de 43 estudiantes desde el 26 de septiembre de 2014 en Iguala (Guerrero), Droncita demandó la renuncia del presidente Enrique Peña Nieto por medio de un video de 40 segundos. A través de agencias humanas y no humanas distribuidas en las imágenes producidas por diversas cámaras con la silueta-grafiti del presidente como fondo, la Droncita se acerca a la cara de la imagen, la pinta de rojo al tiempo que una voz que simula una robot advierte: "Trataste de encuartelar la verdad, trataste de engañarnos. Es tiempo de cambiarlo todo" (ver Figura 3). El vídeo causó un gran impacto en las redes sociales, así como en la prensa nacional e internacional debido su poder para movilizar opinión pública y disputar las versiones oficiales del gobierno en torno a la desaparición de 43 estudiantes.

\section{Figura 4: $\quad$ Drones y arte: Barriletes en las calles de São Paulo}

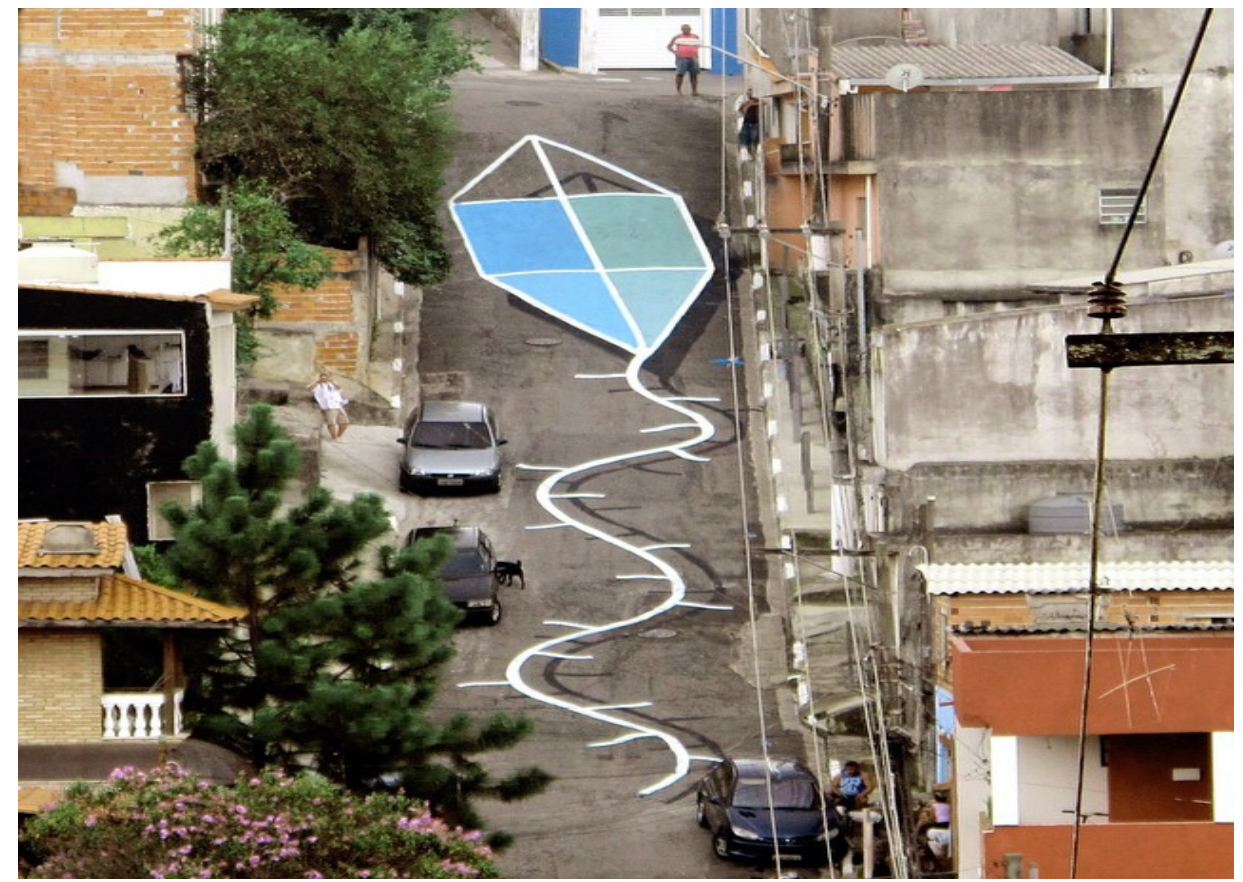

Fuente: Foto de TED.

Otro posible ejemplo lo encontramos en TEC, un artista argentino que pertenece al colectivo multidisciplinario de diseño, música y video experimental "FASE" creado en el año 2000 en Buenos Aires. El artista realiza pinturas de grandes figuras en las calles de São Paulo que incluyen barriletes (también llamados cometas o papalotes), lagartijas, aves y flechas (ver Figura 4). Posteriormente, con la ayuda de un dron, el artista registra sus intervenciones en 
la vía pública con el propósito de jugar con diferentes perspectivas e ilusiones de profundidad (LOQUEVA, 2015). De la misma manera, en Bogotá videos de murales de varios colectivos artísticos, entre los que se encuentran "Toxicomano Callejero" son visualizados por un dron. ${ }^{6}$

Un último ejemplo lo encontramos en el Free Art and Technology Lab, un colectivo de cultura y tecnología en línea dedicado a enriquecer el dominio público a través de la investigación y desarrollo de media technologies. Es un colectivo compuesto por artistas, ingenieros, científicos y activistas, con nodos en 18 países diferentes y una base en la ciudad de Nueva York (EUA). Uno de los artistas de este laboratorio fue el primero en crear lienzos con un dron. En una entrevista, al preguntarle sobre la interacción entre él y el dron para pintar el lienzo, el artista respondió lo siguiente: "... it's like 50 percent me having control and 50 percent the drone" ${ }^{17}$ (Holland, 2014). Su respuesta da cuenta de las agencias distribuidas e interacciones socio-materiales entre drones y humanos. Durante la entrevista el artista también dejo claro que los cuadros, lejos de una mera expresión artística, son un medio de artivismo político que aboga por una mayor rendición de cuentas y responsabilidad en el uso de drones militares (ibídem).

Estos ejemplos muestran cómo las prácticas activistas se fusionan con expresiones artísticas para visibilizar las agencias distribuidas entre humanos y no humanos en una red extensa de tecnologías que van desdedrones, cámaras fotografías, computadoras, dispositivos electrónicos, teléfonos inteligentes, hasta softwares. Así, los drones son capaces de ofrecer diferentes perspectivas visuales, al tiempo de ejecutar intervenciones públicas que también se convierten en un medio que denuncia el contexto militar y autoritario desde el cual emergieron.

\section{Reflexiones finales: Una mirada feminista a los drones}

Las diferentes perspectivas del feminismo enunciadas al principio del artículo (activismo, agencias distribuidas entre actores humanos y no humanos y feminismos globales) han brindado las herramientas necesarias para analizar, a través de ocho casos, el papel de los drones en intervenciones públicas. Los colectivos sociales junto con los drones transgreden los dispositivos de control del cuerpo femenino en Słubice y se oponen a la reapertura de plantas nucleares en Fukui. Sus prácticas cuestionan los sistemas predadores del medio am-

\footnotetext{
${ }^{6}$ Es como si yo tuviera un 50 por ciento del control y 50 por ciento el $d r o n$.

${ }^{7}$ Es como si yo tuviera un 50 por ciento del control y 50 por ciento el $d r o n$.
} 
biente por parte de empresas transnacionales y del gobierno en Rio de Janeiro y Kalimatan, pero también los abusos de poder de los cuerpos de seguridad en la Ciudad de México y en Darmstad. Además, los colectivos contrarrestan el uso militar de los drones al intervenir en el espacio público con obras artísticas en São Paulo, Ciudad de México y Nueva York.

En este artículo he presentado los drones como una tecnología mediadora que disputa el poder de empresas y gobiernos a través de luchas feministas, de la configuración y visibilidad de contra-realidades mediante mapas y cartografías, así como de instrumentos de contra-cultura. Los drones se configuran así como "esos ciborgs de nuestro tiempo" --metáforas de humanos-máquina con agencias distribuidas-- para promover nuevas formas de contra-cultura digital, de participación política y contestación de poder desde los colectivos sociales. Los drones son las tecnologías de este siglo a las que se refiere Haraway que conjugan narrativas de ficción y a la vez visiones parciales y situadas. Son también medios que posibilitan y visibilizan relaciones de poder. Los drones permiten extender el sentido de la visión y embodiment a través de la intervención civil en el espacio aéreo que había sido hasta hace poco apropiado exclusivamente para usos militares, políticos y comerciales. De acuerdo a los ocho casos de colectivos sociales y drones aquí presentados, se desprenden los cuatro siguientes argumentos:

1. Los drones continuarán jugando un papel crucial en tanto tecnologías capaces de intervenir en la esfera pública a través de inesperadas formas de participación política. Las prácticas de los colectivos sociales, en conjunto con los drones, persiguen visibilizar las demandas públicas al crear contra-realidades que disputan las narrativas dominantes de sus usos tradicionales. De esta manera, impugnan el poder de las empresas transnacionales y los Estados generando futuros retos para la gobernabilidad del espacio aéreo como un espacio público.

2. Los drones han promovido el desarrollo de las plataformas transnacionales, comunidades virtuales y laboratorios de ciudadanos al conectar diferentes arenas de lo público (científicos, ingenieros, activistas, empresarios, diseñadores, geógrafos, y pensadores críticos) que demandan una democratización del espacio aéreo.

3. La movilidad de los drones hace visible las diferentes lógicas de lo público, así como las específicas demandas civiles expresadas en las prácticas de participación política en juego. Estas prácticas generan conocimiento civil que se ha materializado en fotos, imágenes, mapas y videos que empodera a los colectivos sociales.

4. A través de representaciones e imaginarios con agencias distribuidas entre una red diferentes actores humanos y no humanos, los drones se convierten en personajes políticos activos en los colectivos sociales como es el caso de la Droncita o el dron japonés. Estos drones son 
producto de un juego complejo entre agencias humanas y materiales, ficciones y realidades situadas cuyas prácticas no se pueden analizar con binarismos.

Por todo lo anterior, una mirada feminista a los drones nos asegurará que cuando los veamos en el cielo más que preocuparnos por el número de mujeres que vuelan drones y los comparemos con los de los hombres, recordemos las enseñanzas que advierten que en un futuro no muy lejano el espacio aéreo, repleto de drones, nos recuerde a nosotras y nuestras luchas diarias también. 


\section{Referencias}

BARAD, K. (2003). Posthumanist performativity : Toward an understanding of how matter comes to matter. Signs, Spring, 803-831. Retrieved from:

$<$ http://philpapers.org/rec/BARPP>

BARAD, K. (2007). Meeting the Universe Halfway: Quantum Physics and the Entanglement of Matter and Meanig. Durham \& London: Duke University Press.

Chávez, E. (2010). Construyendo caminos y esperanzas. Cd. Juárez: Casa Amiga. Centro de Crisis A.C.

Connell, R. (2013). Using southern theory: Decolonizing social thought in theory, research and application. Planning Theory, 13(2), 210-223.

doi:10.1177/1473095213499216

Connell, R. (2015). Meeting at the edge of fear: Theory on a world scale. Feminist Theory, 16(1), 49-66.

doi:10.1177/1464700114562531

Conway, J. (2011). Activist knowledges on the antiglobalization terrain: transnational feminisms at the World Social Forum. Interface: A Journal for and about Social Movements, 3(2), 3364.

DE Soto, P. (2015). Contravisualidad aérea y ciencia ciudadana para el uso de UVAs como tecnología social. Teknokultura: Revista de Cultura Digital y Movimientos Sociales, 12(3), $449-4471$.

Feigenbaum, A. (2015). From cyborg feminism to drone feminism: Remembering women's anti-nuclear activisms. Feminist Theory, 16(3), 265-288.

doi:10.1177/1464700115604132

Halberstam, J. (1991). Automating Gender: Postmodern Feminism in the Age of the Intelligent Machine. Feminist Studies, 17(3), 439-460. Retrieved from:

http://www.jstor.org/stable/3178281?seq=1page_scan_tab_contents

Haraway, D. (1991). Simians, Cyborgs, and Women: The Reinvention of Nature. New York: Routledge.

Haraway, D. (1998). The persistence of vision. In N. Mirzoeff (Ed.), The Visual Culture Reader (pp. 678-684). London: Routledge. 
Haraway, D. (2004). The Haraway Reader: Donna Haraway. London and New York: Routledge. Retrieved from:

$<$ http://www.amazon.com/The-Haraway-Reader-Donna/dp/0415966892>

Holland, A. (2014). Interview: KATSU and The Graffiti Drone. New York: Center for the Study of Drone.

Komarovsky, M. (1950). Functional Analysis of Sex Roles. American Sociological Review, 15(4), 508-516. Retrieved from:

$<$ http://www.jstor.org/stable/2087310?seq=1page_scan_tab_contents $>$

LOQUEVA. (2015). TEC: el argentino que sorpende a Brasil. Retrieved from:

$<\mathrm{http}$ ://loqueva.com/tec-el-argentino-que-sorprende-a-brasil/www.tecalbum.com>

Radjawali, I. \& Pye, O. (2015). Counter-mapping Land Grabs with Community Drones in Indonesia. In Land grabbing, conflict and agrarian-environmental transformations: perspectives from East and Southeast Asia. An international academic conference.

Sandoval, C. \& Latorre, G. (2008). Chicana/o Artivism: Judy Baca’s Digital Work with Youth of Color. En A. Everett (Ed.), Learning Race and Etnicity: Youth and Digital Media (pp. viiix). Cambridge: MIT Press.

Stone, Z. (2015). Disarming The Drone Gender Gap. Retrieved April 6, 2016, from: $<$ http://www.buzzfeed.com/zarastone/disarming-the-drone-gender-gap.eeO816gXy>

Suchman, L. (2007). Human-Machine Reconfigurations: Plans and Situated (Cambridge.). New York: cambridge University Press. Retrieved from:

$<$ http://www.cambridge.org/de/academic/subjects/psychology/developmentalpsychology/human-machine-reconfigurations-plans-and-situated-actions-2nd-edition> 